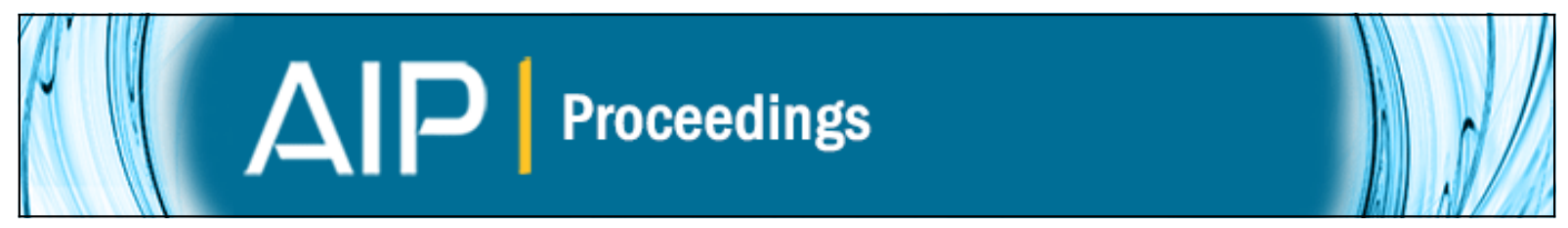

\title{
Brominated carbon black: An EDXD study
}

Marilena Carbone and Lorenzo Gontrani

Citation: AIP Conference Proceedings 1603, 47 (2014); doi: 10.1063/1.4883041

View online: http://dx.doi.org/10.1063/1.4883041

View Table of Contents: http://scitation.aip.org/content/aip/proceeding/aipcp/1603?ver=pdfcov

Published by the AIP Publishing

Articles you may be interested in

High pressure Raman and EDXD study of diaspore

AIP Conf. Proc. 309, 1535 (1994); 10.1063/1.46375

Erratum : XRay Diffraction Study of Four Reinforcing Carbon Blacks

J. Chem. Phys. 24, 1118 (1956); 10.1063/1.1742714

XRay Study of the Graphitization of Carbon Black

J. Appl. Phys. 25, 1503 (1954); 10.1063/1.1702373

An XRay Study of Carbon Black

J. Appl. Phys. 13, 364 (1942); 10.1063/1.1714879

XRay Diffraction Study of Carbon Black

J. Chem. Phys. 2, 551 (1934); 10.1063/1.1749528 


\title{
Brominated Carbon Black: an EDXD Study
}

\author{
Marilena Carbone ${ }^{1}$, Lorenzo Gontrani ${ }^{2,3, a)}$ \\ Università di Roma Tor Vergata, Via della Ricerca Scientifica 1 I-00133 Roma, \\ Italy \\ ${ }^{1}$ Università di Roma Tor Vergata, Via della Ricerca Scientifica 1 I-00133 Roma, Italy \\ ${ }^{2}$ CNR-Istituto di Struttura della Materia, Via del Fosso del Cavaliere, I-00133 Roma, Italy \\ ${ }^{3}$ Dipartimento di Chimica- Università Sapienza, P.le Aldo Moro 5, I-00184 Roma, Italy \\ ${ }^{a)}$ Corresponding author: lorenzo.gontrani@uniroma1.it
}

\begin{abstract}
An energy dispersive X-Ray study of pure and brominated carbon black was carried out. The analysis of the diffraction patterns reveals that the low bromine load $(c a .1 \% \mathrm{~mol})$ is trapped into the structure, without significantly modifying it. This allows the application of the difference methods, widely tested for electrolyte solutions, inorganic matrices containing metals and isomorphic substitutions.
\end{abstract}

Keywords: Carbon Black, EDXD, Bromine, Diffraction

PACS: 61,82

\section{INTRODUCTION}

Carbon black is a widely used material in many applications. It can be used as filler in elastomers, plastics and paints, to modify the mechanical, electrical and optical properties of the materials it is dispersed in. When embedded in plastics it imparts UV protection, electrical conductance and range of darkness and reinforcement. When used as filler in rubbers it changes the fracture behavior, improves abrasion and failure properties. Carbon black is electrically conductive and imparts good conductivity to thermoplastic polymers [1-5]. Furthermore, it is used as pigment in xerographic toner since it plays a role in maintaining a suitable level in electric charge on the toner.

Carbon black primary characteristics responsible for its properties are the particle size, the aggregate size, the morphology and microstructure of the aggregates, porous structure, nature of the surface, surface area [6]. Carbon black technical performances may be improved by halogenation and bromination, in particular [7].

Furthermore, brominated carbon systems are synthons for further derivatization, since they are chemically reactive and the $\mathrm{Br}$ atoms can be substituted by alcohols (Williamson ether synthesis or Grignard Reactions) or glycols, etc., but more importantly by amines or diamines, too. Using this approach a covalent bonding of organic molecules or polymers onto the carbon material surfaces is possible and a wide range of new applications is on the horizon. Besides, $\mathrm{Br}$ addition on graphene lattice $\mathrm{sp}^{2}$ carbon atoms $\mathrm{sp}^{3}$ hybridized carbon atoms at domain edge or defects are also available for substitution or other reactions.

Several chemico-physical methods were used for bromination of carbon system including the use of bromine, bromoform and mixtures of both. Plasma reactions yield highly effective, highly selective bromination, expressed as absence of side-reactions. Microwave methods may also be used, in the spark-assisted variant [8]. The resulting graphite halide can easily be exfoliated into monolayer graphene in organic solvents. The bromination may occur as a radical substitution of hydrogen by bromine atoms [9] or as an addition to a carbon-carbon double bond. A recently reported method for bromination of carbon systems is an ultrasound assisted one [10].

The structural properties of carbon-based materials upon bromination are method- and mechanism-dependent. As for carbon black, both covalent bromine-carbon bonds and molecular bromine entrapment are possible interactions. In the current paper, microwave-assisted bromination was used as carbon black halogenation method. The product were, then, studied by Energy Dispersive X-ray Diffraction. In particular, in order to isolate the contribution of the $\mathrm{C}-\mathrm{Br}$ interaction from the overall curve, the difference method was applied, i.e. scattered intensities of the 
brominated and non-brominated couples of carbon systems were collected and normalized. Subsequently, the scattered intensity of the non-brominated compound was subtracted from the corresponding brominated one.

This method, originally developed for isomorphic electrolyte solutions and later on applied to $\mathrm{SiO}_{2} \mathrm{matrices}$ containing small traces of different metals and to bromine salts [11-17], is based on the assumption that the solute/matrix concentration (carbon black in this case) is almost identical in the samples, so that its scattering contribution can be regarded as a constant and can be subtracted from the total curve to obtain a difference spectrum to which only the remaining structural correlations contribute.

\section{Experimental Methods}

A weighed amount of carbon black N220 was placed in a $50 \mathrm{ml}$ round bottomed flask, then liquid bromine was added and the flask was tightly closed with a glass stopper and with a rubber band to avoid any bromine leakage. The mixture was sonicated by submerging large part of the round-bottomed reaction flask inside the tank of the ultrasonic cleaner which was filled with water at the suggested filling level. After $2 \mathrm{~h}$ sonication, the bromine in excess was distilled off under reduced pressure.

Energy Dispersive X-ray Dispersion (EDXD) measurements of the two samples were performed using a noncommercial energy scanning diffractometer [18-20]. The white Bremsstrahlung emitted by a tungsten tube (50 $\mathrm{kV}, 40 \mathrm{~mA}$ ) was used as radiation source. The samples were loaded in a quartz capillary $(2 \mathrm{~mm}$ diameter, $80 \mathrm{~mm}$ length). Scattering intensities of the sample were obtained by merging several measurements performed in correspondence of eight scattering angles $\theta=24^{\circ}, 15.5^{\circ}, 5^{\circ}, 10.5^{\circ}, 8^{\circ}, 3^{\circ}, 1^{\circ}, .5^{\circ}$. The larger number of angles than normally used in this technique, where five angles are enough to yield $\mathrm{I}(\mathrm{q})$ spectra (see below) ranging from 0.12 to $19.56 \AA^{-1}[21]$, was necessary because bromine fluorescence lines fall amid the bremsstrahlung, so that the usable portion of the radiation is beyond bromine $\mathrm{K}_{p}$ line. The presence of the very sharp bromine fluorescence lines is clearly visible in the diffracted intensity $v s$ energy pattern registered, for instance, at 15.5 degrees, see Fig. 1 . The expression for $\mathrm{q}$ is $\mathrm{q}=\cos { }^{*} \mathrm{E}^{*} \sin \theta$, where cost is equal to 1.014 when $\mathrm{E}$ is expressed in $\mathrm{keV}$ and $\mathrm{q}$ in $\AA^{-1}$. The primary beam intensity $\mathrm{I}_{0}(\mathrm{E})$ was measured

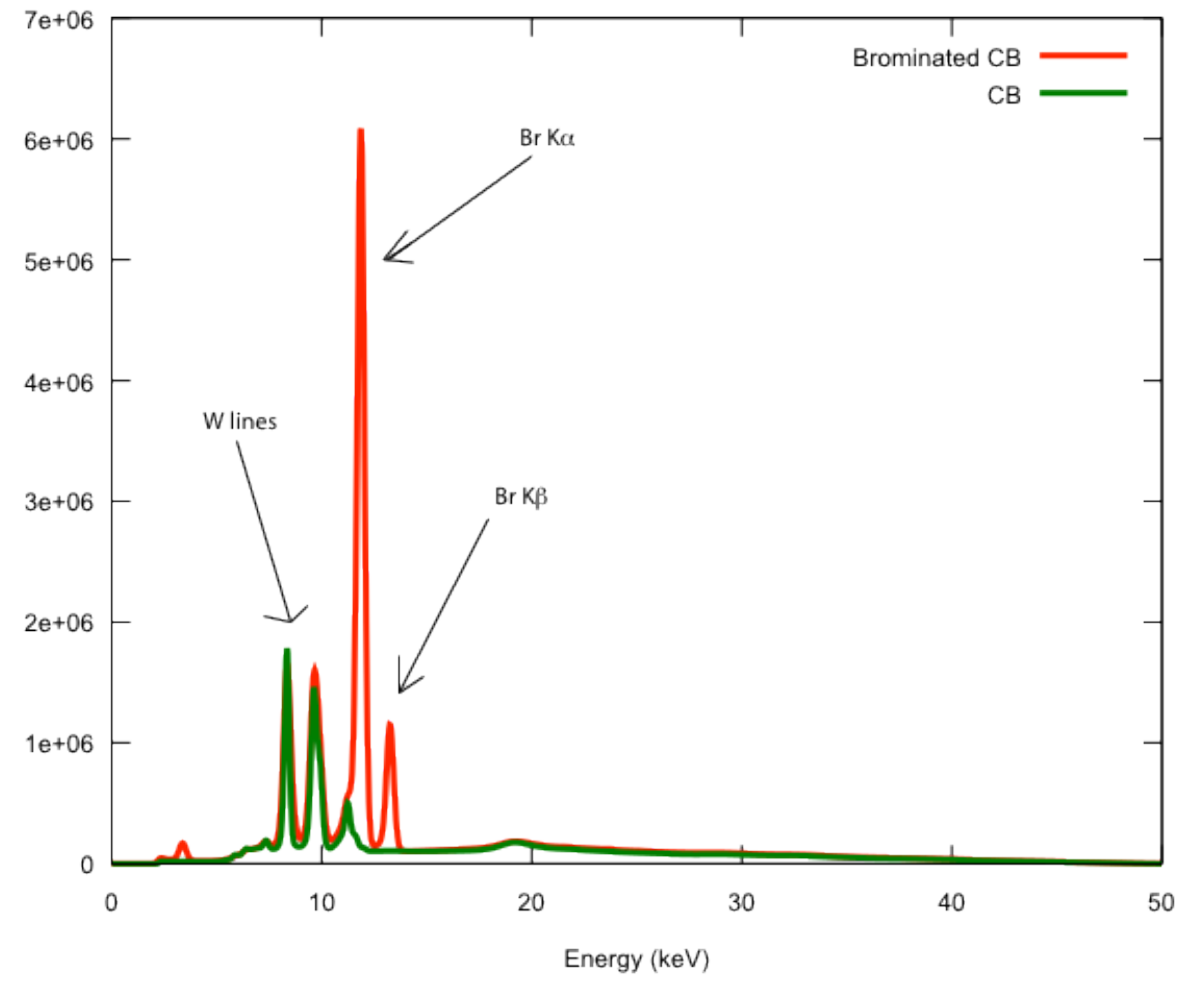

FIGURE 1 - Diffracted intensity measured at $\theta=15.5^{\circ}$. Brominated Carbon Black: red; Carbon Black: green 
directly, by reducing the tube current to $10 \mathrm{~mA}$ without the sample with the two slits after the source and before the detector "closed" (i. e. very narrow). Transmission of the samples and of the empty capillary was measured under the same conditions. Both quantities are needed to carry out the necessary absorption corrections to experimental data [22]. The various angular data were normalized to a stoichiometric unit of volume containing one carbon atom and merged to yield the scattered intensity, $\mathrm{I}_{\mathrm{E} . \mathrm{U}}$. (q), expressed in electron units. Finally, the

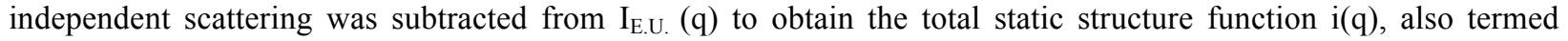
"reduced intensity", according to the relation

$$
i(q)=I_{E . U .}(q)-\sum x_{i} f_{i}^{2}
$$

In this equation, $\mathrm{x}_{\mathrm{i}}$ and $\mathrm{f}_{\mathrm{i}}$ are the number concentration and the scattering factor of carbon atoms, respectively. This function was multiplied by $\mathrm{q}$ and by a q-dependent sharpening factor, $\mathrm{M}(\mathrm{q})$, to improve the curve resolution at high q. The expression for $\mathrm{M}(\mathrm{q})$, using carbon as the "sharpening atom", is

$M(q)=\frac{f_{C}^{2}(0)}{f_{C}^{2}(q)} \exp \left(-0.01 \mathrm{q}^{2}\right)$

The structure function pattern were then Fourier-Transformed to obtain the Radial Distribution Function in distance space, according to the relation

$$
D(r)-4 \pi r^{2} \rho_{0}=4 \pi r^{2} \rho_{0}(G(r)-1)=\frac{2 r}{\pi} \int_{0}^{\infty} q i(q) M(q) \sin (r q) d q
$$

All data treatment was performed with in-house written codes.

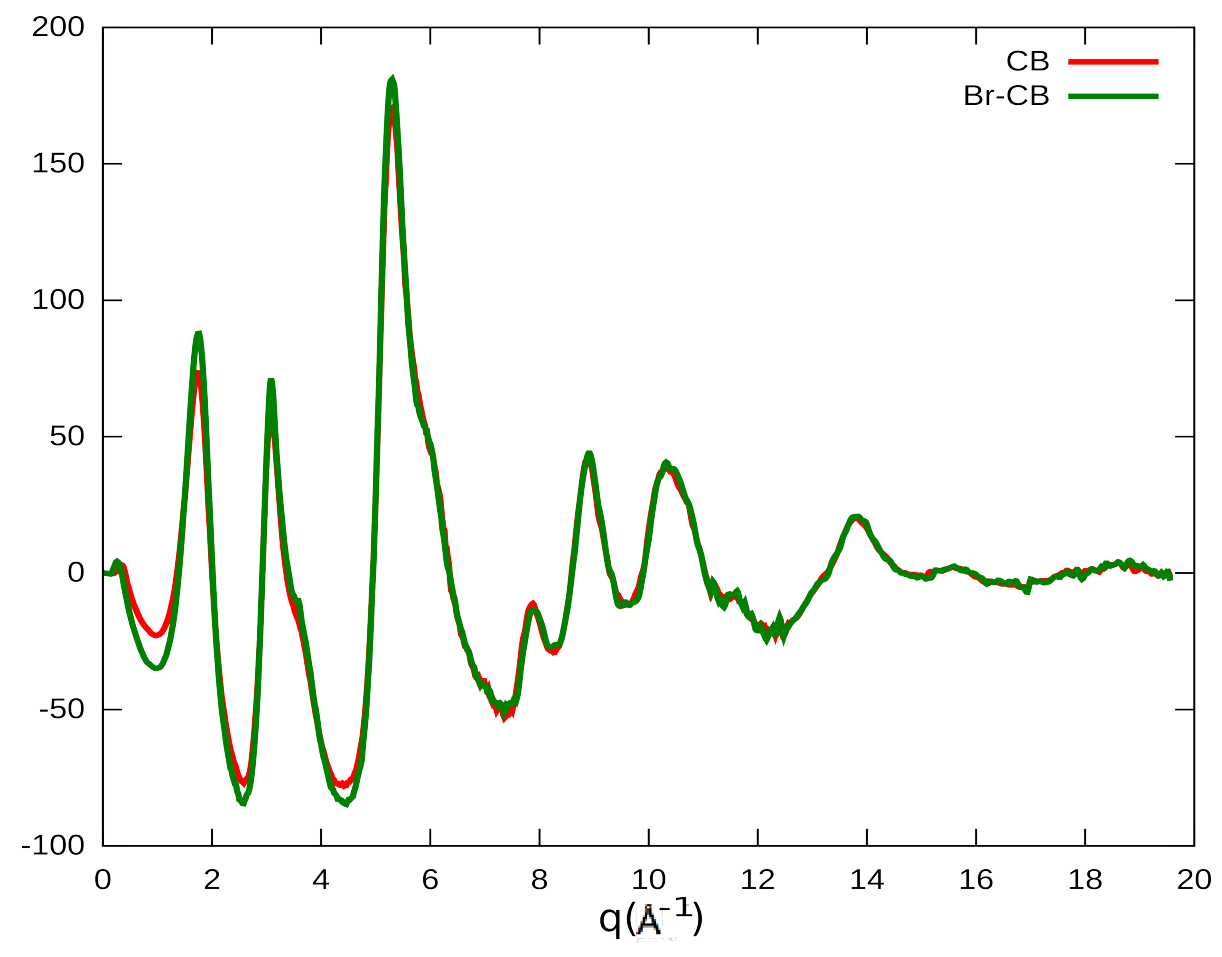

FIGURE 2 - Structure Function qI(q)M(q); Brominated Carbon Black (green); Carbon Black (red) 


\section{Results and Discussion}

The measured structure functions are plotted in Fig. 2 (CB, green; Br-CB, red) and show patterns of large peaks typical of amorphous systems. Overall, the two functions show several differences, despite the very small concentration of bromine (1.0\% molar ratio). In particular, a general increase of peak height is observed in the low $\mathrm{q}$ and central region of the spectrum. The pre-peak (or FSDP, First Diffraction Peak) position moves from $0.34 \AA^{-1}$ in pure $\mathrm{CB}$ to $0.28 \AA^{-1}$ in $\mathrm{Br}-\mathrm{CB}$, while the two tallest peaks $\left(1.70\right.$ and $\left.5.30 \AA^{-1}\right)$ gain intensity without changing position. All these features can be associated with the formation of new carbon-bromine and bromine-bromine contacts that are longer than carbon-carbon ones, causing an overall increase of longer structural correlations. The dependence of the peak position on the distance of two individual point scatterers is originated by the cardinal sine function (sinc) of the Debye formula [23]:

$$
I(q)=\sum_{i \neq j} x_{i} x_{j} f_{i} f_{j} \frac{\sin \left(q r_{i j}\right)}{q r_{i j}} * \exp \left(-0.5 q^{2} \sigma_{i j}^{2}\right)
$$

In this expression, $\mathrm{f}_{\mathrm{ij}}$ and $\mathrm{x}_{\mathrm{ij}}$ are the $\mathrm{q}$-dependent scattering factors and the numerical concentration of the scatterers respectively, $\mathrm{r}_{\mathrm{ij}}$ is the relative distance and $\sigma_{\mathrm{ij}}$ a Gaussian-type strain function associated to it, necessary to model the spatial uncertainty when a single model configuration is used. As regards the two pre-peaks, they are generally attributed to medium-range order in liquids and amorphous solids [24, 25], and are related to effective Bragg distances $(2 \pi / q)$ occurring in the partially ordered system, that correspond to $18.48 \AA$ and $22.44 \AA$ in distance space, respectively. Qualitatively speaking, all features seem to indicate that the insertion of even smaller quantities of bromine (1\%) into CB structure causes the system to enlarge, if not to swell.

A further structural analysis was carried out according to the method based on difference curves. In Br-CB spectrum, once $\mathrm{CB}$ curve has been taken out, only $\mathrm{Br}-\mathrm{Br}$ and $\mathrm{Br}-\mathrm{C}$ contributions are left. The difference curve $\mathrm{Br}-$ $\mathrm{CB}-\mathrm{CB}$ is reported in Fig. 3. The already marked increase of peak heights already discussed for Fig. 2 is very evident in the difference curve.

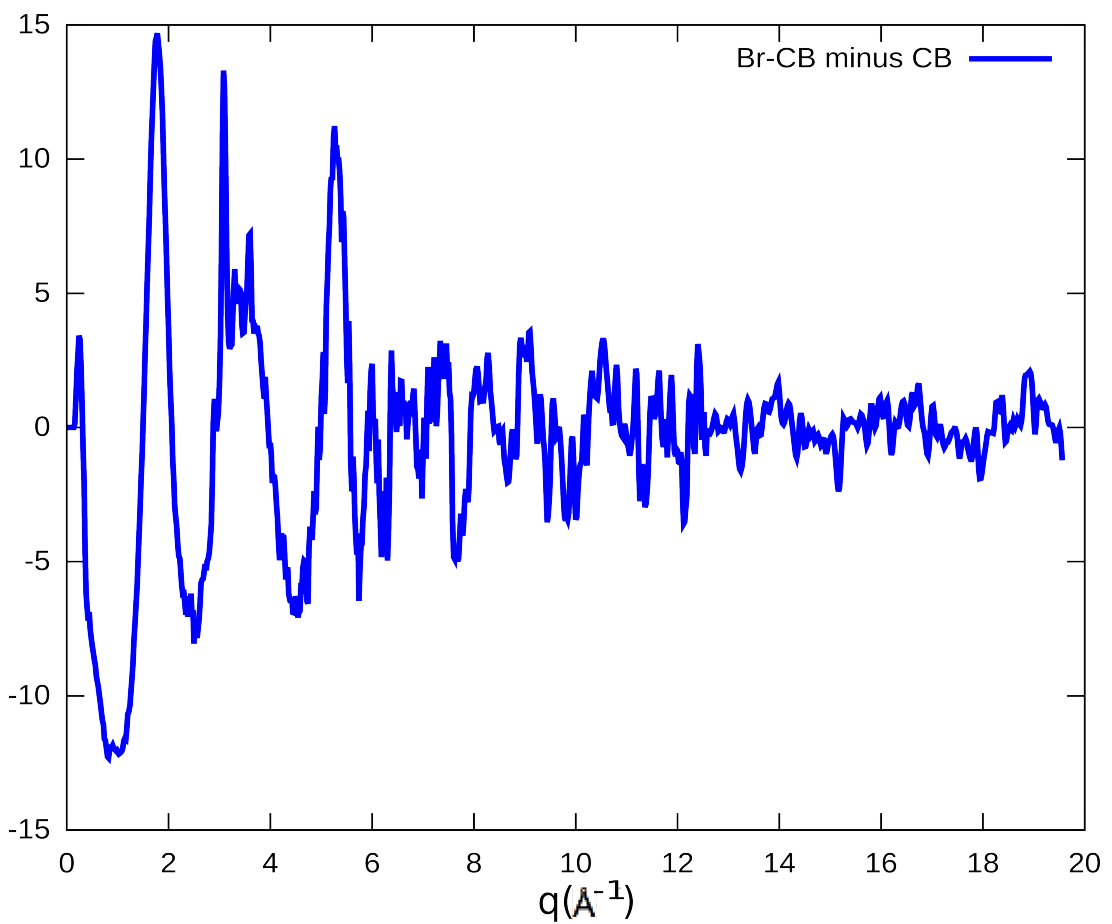

FIGURE 3 - Difference Structure Function qI(q)M(q): brominated Carbon Black minus Carbon Black 
The presence of new $\mathrm{Br}-\mathrm{C}$ contacts in the $\mathrm{Br}-\mathrm{CB}$ sample is more evident in the difference between Radial Distribution Functions $\mathrm{D}(\mathrm{r})(\mathrm{Br}-\mathrm{CB})-\mathrm{D}(\mathrm{r})(\mathrm{CB})$, reported in Fig. 4. Among these contacts, though, the presence of covalent bonds between carbon and bromine is negligible, since there is no peak around 1.9-2.0 $\AA$. The first visible peak is at $2.30 \AA$, and corresponds to the typical $\mathrm{Br}-\mathrm{Br}$ distance of diatomic molecular bromine; all the peaks that follow can be ascribed to larger bromine-carbon contacts.

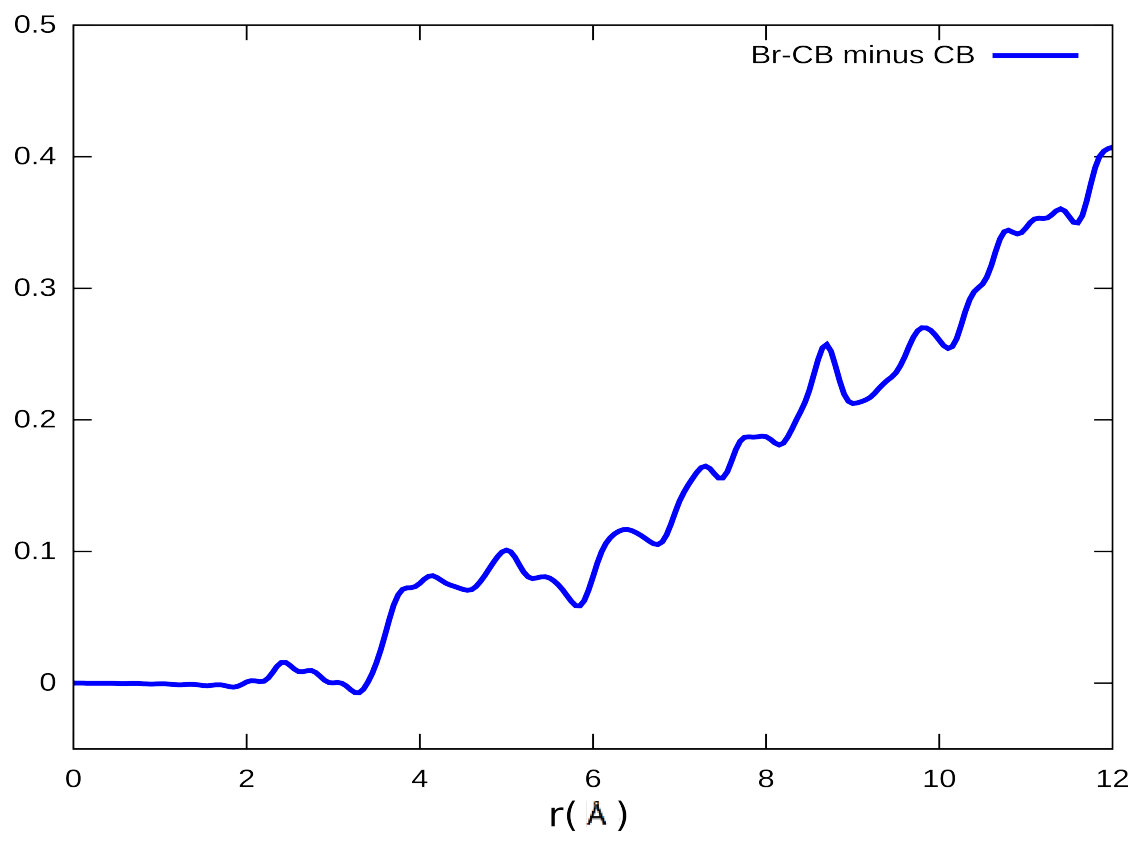

FIGURE 4 - Difference Radial Distribution Function D(r): brominated Carbon Black minus Carbon Black

\section{CONCLUSIONS}

Carbon black N220 and its brominated analogue, obtained by an ultrasound assisted procedure, were investigated by Energy Dispersive X-ray Diffraction. In spite of the low bromine load (1\%) structural information could be achieved, by application of the difference method. It was found that the first structural peak in the difference radial curve corresponds to the typical distance of molecular bromine, which appears to be the dominant species embedded in the carbon black matrix.

\section{ACKNOWLEDGMENTS}

The authors wish to thank Prof. Ruggero Caminiti for providing EDXD spectra and for general guide and assistance and Dr. Franco Cataldo for providing the samples. Computational support from CASPUR (grant std11465, std12-011) is acknowledged; L. G. acknowledges support from FIRB (RBFR086BOQ)

\section{REFERENCES}

1 Carbon Black, Science and Technology Ed., edited by J. -B. Donnet, R. C. Bansal and M. -J. Wang

2 M. Maiti, S. Sadhu and A.K. Bhowmick, J. Appl. Polymer Sci. 96, 443-451 (2004)

3 T. Mabuchi, K. Muraoka and T. Mizoguchi Polymer Preprints, Japan, 54(2), 1164 (2005)

4 K. Pal, S. K. Pal, C. K. Das and J. K. Kim, Adv. Struct. Mat. 9, 201-231 (2011) 
5 F. Cataldo, Polymer Int. 50, 828-834 (2001)

6 J.-B. Donnet, Carbon 32(7), 1305-1310 (1994)

7 E. Papirer, R. Lacroix, J.-B. Donnet, G. Nanse and P. Fioux, Carbon 32(7), 1341-1358 (1994)

8 A. Lippitz, J. F. Friedrich and W. E. S. Unger, Surf. Sci. 611, L1-L7 (2013)

9 J. Zheng, H.-T. Liu, B. Wu, C.-A. Di, Y.-L. Guo, T. Wu, G. Yu, Y.-Q. Liu and D.-B. Zhu, Scientific Reports 2, Article number $662(2012)$

10 F. Cataldo, L. Lilla and O.Ursini, Fullerenes, Nanotubes and Carbon Nanostructures 47, 357 (2013)

11 R. Caminiti, C. Sadun, M. Basanisi and M. Carbone, J. Mol. Liquids 70, $55-70$ (1996)

12 L. Abis, D. Belli Dell'amico, F. Calderazzo, R. Caminiti, F. Garbassi, S. Ianelli, G. Pelizzi, P. Robino and A. Tomei, J. Mol. Cat. A 108(3), L113-L117 (1996)

13 R. Caminiti, M. Carbone, C. Sadun and G. Mancini, J. Mater. Chem. 7, 1331-1337 (1997).

14 L. Abis, D. Belli Dell'amico, C. Busetto, F. Calderazzo, R. Caminiti, C. Ciofi, F. Garbassi and G. Masciarelli, J. Mater. Chem. 8 (3), 751-759 (1998)

15 R. Caminiti, M. Carbone and C. Sadun, J. Mol. Liquids, 75, 149-158 (1998)

16 L. Gontrani, R. Caminiti, L. Bencivenni and C. Sadun, Chem. Phys. Lett. 301 (1), 131-137 (1999)

17 D. Atzei, T. Ferri, C. Sadun, P. Sangiorgio and R. Caminiti, J. Am. Chem. Soc. 123 (11), 2552-2558 (2001)

18 M. Carbone, R. Caminiti and C. Sadun, J. Mater. Chem. 6, 1709-1716 (1996).

19 V. Rossi Albertini, V., L. Bencivenni, R. Caminiti, F. Cilloco and C. Sadun, J. Macromol. Sci., Phys. B35 (2), 199 (1996)

20 R. Caminiti, M. Carbone, S. Panero and C. Sadun, J. Phys. Chem. B 103(47), 10348-10355 (1999)

21 V. Migliorati, P. Ballirano, L. Gontrani, A. Triolo and R. Caminiti, J. Phys. Chem. B, 115, 4887 (2011)

22 Y. Murata and K. Nishikawa, Bull. Chem. Soc. Jpn., 51, 411 (1978)

23 T. Wieder and H. Fuess, H, Z. Naturforsch., A: Phys. Sci., 52a, 386 - 392 (1997)

24 O. Russina, A. Triolo, L. Gontrani and R. Caminiti, J. Phys. Chem. Lett. 3(1), 27-33 (2012)

25 P. H. Gaskell, J. Non-Cryst. Solids 351(12-13), 1003-1013 (2005) 